International Journal of Instruction e-ISSN: 1308-1470 • www.e-iji.net

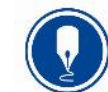

January $2022 \bullet$ Vol.15, No.1

p-ISSN: 1694-609X

pp. 1065-1080

Article submission code:

20210213164157
Received: 13/02/2021

Revision: 07/09/2021
Accepted: 01/10/2021

OnlineFirst: 24/12/2021

\title{
Learning Taekwondo Martial Arts Lessons Online: The Perspectives of Social Cognitive Career and Motivation Theory
}

\section{Luis Miguel Dos Santos}

Asst. Prof., Woosong Language Institute, Woosong University, South Korea, luisdossantos@woosong.org

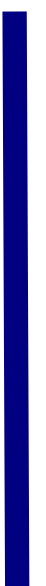

The application of computer-aided teaching and learning approaches is not uncommon in many school environments. However, due to the traditional practices, most of the practice-based courses have still relied on face-to-face teaching methods. Because of the COVID-19 pandemic, most programmes have been moved to the online platform. With the case study design, the scholar interviewed 12 participants who have sent students to one of the distance learning based martial arts education courses. Based on the Social Cognitive Career Theory and Social Cognitive Career and Motivation Theory, this project sought to understand the motivation and reasons why do parents want to send students to an online martial arts afterschool programme? The finding showed that the achievements of education and career goals played roles in the motivation and reasons of these groups of parents, regardless of the outcomes of the programmes and the willingness of students. The results of this study provided a blueprint for government leaders, policymakers, school leaders, parents, students, and researchers to understand the current social problem, such as computer-aided tools.

Keywords: computer-aided teaching and learning, martial arts, online education, online programmes, social cognitive career and motivation theory, Taekwondo

\section{INTRODUCTION}

The application of computer-aided teaching and learning approaches in the current education system (traditional-age students' classroom, vocational-based courses, and adult learning) has raised concerns and prompted confusion around the applications, effectiveness, expectations, experiences, and outcomes related to these distance-based materials and teaching (Dos Santos, 2019a, 2020f; Espino et al., 2020; Santagata \& Guarino, 2011). Traditional approaches, such as face-to-face teaching, practical-based, and internship-based) for pre-12 education and schooling usually involve in-person teaching with computer-aided materials delivered in classrooms (Weiner, 2012; Weiner \& Jerome, 2016). However, because of the COVID-19 pandemic, many education institutions have moved to online learning in order to prevent infection for all parties (Simpson, 2018).

Citation: Dos Santos, L. M. (2022). Learning taekwondo martial art lessons online: the perspectives of social cognitive career and motivation theory. International Journal of Instruction, 15(1), 1065-1080. https://doi.org/10.29333/iji.2022.15160a 
Online learning is not a new teaching and learning approach or strategy (Brown et al., 2015; Yamagata-Lynch et al., 2015). However, many learners in the Far East region(s), particularly South Koreans, do not have previous experience of online classrooms (it is less likely that South Korean learners experienced online classrooms before the COVID19 pandemic). Recently, a few projects have studied voices from both students and teachers (Cavus, 2015; Elyakim et al., 2019). However, it is important to understand how parents understand and describe these online learning experiences and the expectations of their children during the COVID-19 pandemic.

Martial arts, which students learn in in-person classrooms, involve practical-based interactions rather than cognitive learning or paper-based exercises (Lantz, 2002). In martial arts education, teachers demonstrate the behaviours, the students follow the same performance(s) and procedures, and the teachers offer constructive comments for students' improvement. Also, teachers should teach breathing performances to conduct exercises and performances, as the interactions and performances need both psychological and physical behaviours and understanding (Nosanchuk, 1981).

Some recent studies (Brown et al., 2015; Dos Santos, 2020b; Yamagata-Lynch et al., 2015), online teaching and learning should offer materials for cognitive development and textbook-oriented knowledge. Learners would gain expected results through theoretical knowledge and practice. However, as some practical and vocational performance and ideas could need to be demonstrated by teachers, it could become a question of how students can gain these skills from online materials. A recent study (Burdina et al., 2019) also indicated an educational trend for primary schools for online learning options, especially in remote regions.

Because of the recent COVID-19 pandemic (social distancing recommendation) and the application of computer-aided teaching and learning approaches, schools and universities have moved to online learning based classrooms. From early 2020, some government departments (in South Korea and many international countries and regions) required their educational institutions, regardless of their status and subject matter, to move to online platforms. It was expected that kindergarten, primary and secondary schools and universities should be prepared to make this move to online classrooms, as much of the instructions and lectures involve cognitive-based learning materials. However, practical-based courses (in this case, martial arts lessons) may experience concerns and confusion, as their instructions could only be taught via in-person and performance-based instructions. Lassoued et al. (2020) argued that because of the COVID-19 pandemic, courses had been switched online to prevent in-person risks in the classrooms. In addition, Petrenko et al. (2020) argued that the applications of delivering vocational courses via online learning prompt problems about the tailor-made coursework curriculum, effective exchanges between teachers and students, useful interactions between students, and practical exercises with effective comments (Freer \& Evans, 2019). 


\section{Purpose of the Study}

This project aims to explore the motivation and reasons (behind) why South Korean parents decide to send their school-age student(s) to one online martial arts (i.e., Taekwondo) course. The scholar wanted to use the voices of the parents but not the students for this project. First, although underage students have their own preferences in martial arts learning, many accepted their parents, teachers, and counsellors' recommendations and ideas for their delivery tools. Therefore, the scholar sought the voices from the parents' perspective (in order to understand the decision-making process of the parents, as the decision-maker of the martial arts study). Second, some people argue that online courses and practical knowledge and performance do not have effective outcomes (without in-person interactions). Therefore, it is essential to understand why these parents decided to send their students to these online courses. This project did not focus on measurements of effectiveness or grading improvement(s) but the decision-making process and motivation(s). Therefore, this project was guided by the following research question:

- Why do parents want to send their students to an online martial arts (i.e., Taekwondo) school? What are the motivations and reasons behind this decisionmaking process?

The results of this project will provide some recommendations and ideas for school leaders, parents, students, and instructors in regard to how to reform martial arts education, improve practical-based curricula, and select online teaching and learning programmes.

\section{Theoretical Framework}

To upgrade the confirmation of the study, the scholar employed two theoretical frameworks in this study, including the Social Cognitive Career Theory (Lent et al., 1994; Lent \& Brown, 1996) and the Social Cognitive and Motivation Theory (Dos Santos, 2021; Lent et al., 1994; Lent \& Brown, 1996) as the tools.

First of all, the Social Cognitive Career Theory is one of the popular approaches and theories in motivation, reasons, and career decisions. The theory was originally developed by (Lent et al., 1994; Lent \& Brown, 1996). The theory focused on how individuals decide their decision-making process(es) based on three points: 1) achievement of education and career goals, 2) academic and career interests, and 3) interests of career developments. However, based on the behaviours of the individuals and the foundation of the theory, the current Social Cognitive Career Theory was developed based on the recommendation of some applied studies. As an outcome, the current version of the Social Cognitive Career Theory concerns the understanding and relationships among four factors: 1) interests of career developments, 2) achievements of education and career goals, 3) academic and career interest, and 4) financial consideration (Kwee, 2020).

Second, over the last few decades, a large number of researchers and scholars employed this theory in studies about career development (Dos Santos, 2020a), motivation (Dos 
Santos, 2018a), foreign language teaching and learning (Dos Santos, 2018b), teachers' professional development, and individuals' academic decision (Brown \& Lent, 2019; Flores \& O'Brien, 2002; Gibbons and Shoffner, 2004; Thompson et al., 2017). In 2021, an educational and psychological researcher and educator (Dos Santos, 2021) developed a new theory called the Social Cognitive Career and Motivation Theory based on the ideas of Social Cognitive Career Theory. The Social Cognitive Career and Motivation Theory (Dos Santos 2021) further advocated that the psychological and internal factors with self-efficacy, and social external factors, may highly influence the motivation and decision-making process of the individuals. As a result, the current study concerned about these two factors with six elements, including academic interests, personal considerations, achievements of education and career goals; interests in career development, financial considerations, and surrounding environments and individuals, and applied these directions as the lens for the findings and discussions.

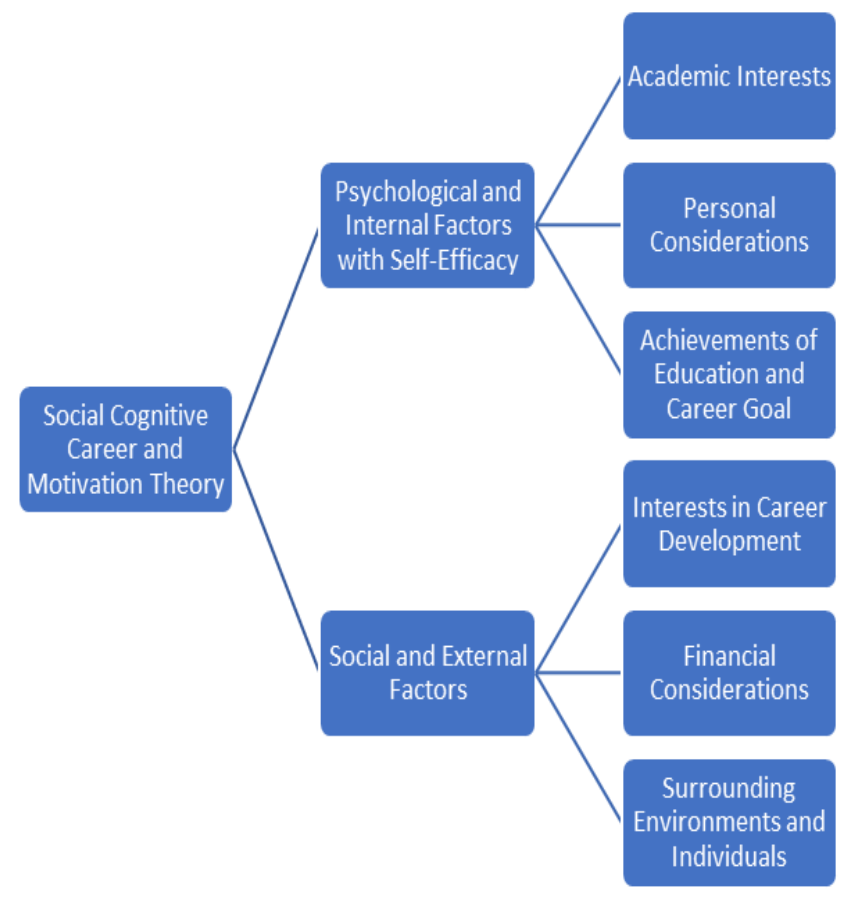

Figure 1

Social cognitive career and motivation theory (Dos Santos, 2021)

\section{METHOD}

The current study employed the qualitative research method (Tang \& Dos Santos, 2017) as the application tool for the research methodology. The scholar sought to investigate the motivation(s) and the reason(s) why do parents want to send their students to online martial arts (i.e., Taekwondo) schools? What are the motivations and reasons behind this decision? 


\section{Research Design: Case Study}

The case study methodology was employed. The exploratory embedded single-case study research design was used in this study (Yin, 2012). The case for this study was located in an afterschool programme (martial arts school), in this project, in South Korea. The case study was employed because the scholar wanted to understand how the individuals in a particular site describe their experience about the online teaching and learning experience and approach of martial arts education.

\section{The Participants}

The participants were parents of a group of students who are currently enrolled at an online martial arts education in a South Korean academy (i.e. afterschool programme/school). The purposive sampling was used to recruit the participant as the scholar is an educational scholar in the East Asian region. Therefore, the scholar has professional connections with different educational institutions for potential research studies.

First, the scholar asked the site manager for the arrangement verbally. The manager agreed with this project. Second, the scholar sent the aims of this project, research protocols, agreement forms, and related materials to the site manager. Third, the site manager asked for an electronic invitation to all potential participants (i.e. parents) in their school. Fourth, after several rounds of discussion(s), 12 participants would like to join this project.

\section{Data Collection}

Because of the COVID-19 pandemic and the recommendation of the social distancing, only a few ways could be conducted for qualitative data collection. In this project, the Zoom-based interview tool was used. The scholar used the interview (semi-structured) and focus groups on collecting voices with the connection of the research question based on the lens of the Social Cognitive Career Theory and Social Cognitive Career and Motivation Theory (Dos Santos, 2018a, 2019b, 2020c, 2020d, 2021; Lent et al., 1994; Lent \& Brown, 1996).

The participants were interviewed privately based on the interview protocol. The participants were free to share their ideas, concerns, and difficulties based on the internal problems and external problems from families, society, and self-understanding. Each interview session lasted from 45 minutes to 53 minutes.

After the participants completed their individual interview(s), the scholar established the focus groups for group discussions. Four participants joined each of the focus group(s). Therefore, three focus groups were established. Each focus group lasted from 67 minutes to 88 minutes.

After the scholar summarised and studied the materials, the scholar sent the related materials to the participant for member checking. The member checking interview sessions were hosted online. Each member checking interview session lasted from 23 minutes to 45 minutes. All participants agreed and confirmed their own data. During the 
data collection procedure(s), the scholar employed a digital recorder for recording. All agreed with the arrangement of the interview procedure. Figure 2 outlines the data collection procedure.

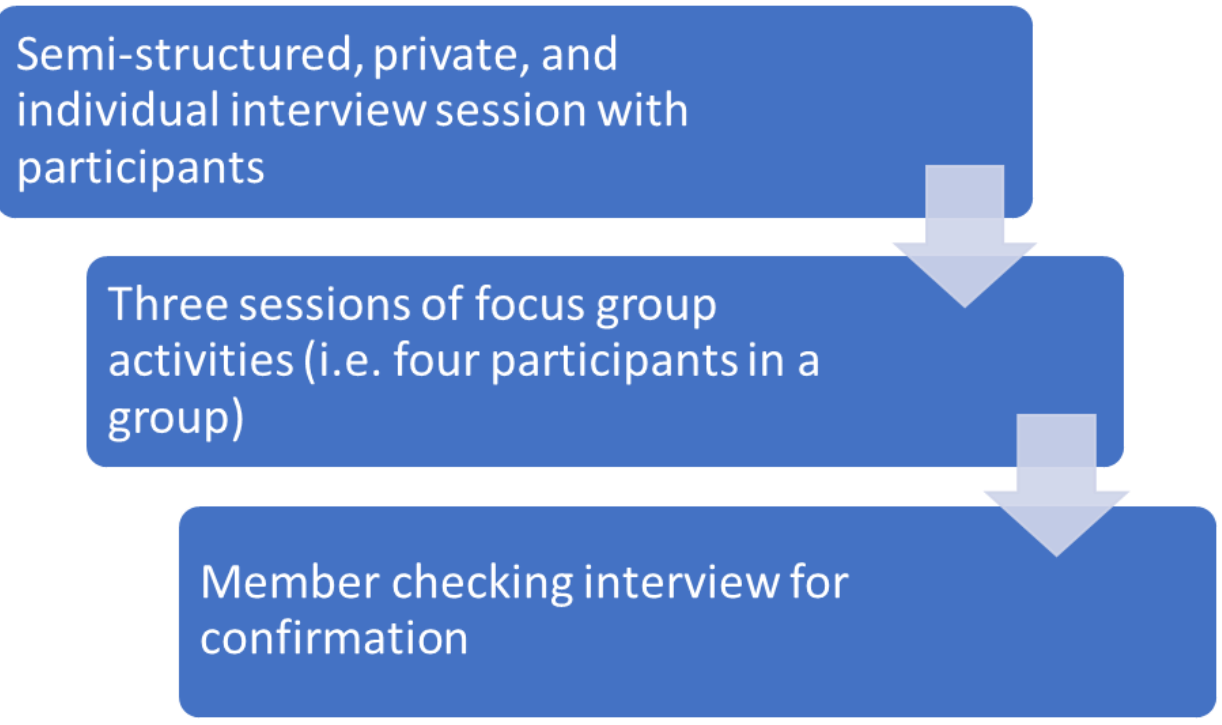

Figure 2

Data collection procedure

\section{Data Analysis}

After the scholar completed the data collection step, the scholar transcribed the voiced messages into written transcripts. The scholar re-read the transcripts several times for the meaningful themes and subthemes based on the guideline from the general inductive approach (Thomas, 2006).

The scholar first employed the open-coding technique to categorise the large-size transcripts into the first-level themes and subthemes (Merriam, 2009). During this time, the scholar grouped 15 themes and 18 subthemes. However, an effective qualitative research study should have narrowed groups for reporting. Therefore, the scholar employed the axial-coding technique for second-level themes and subthemes. As a result, two themes and five subthemes were merged (Merriam, 2009).

\section{Human Subject Protection}

The privacy of the participants was the most important part of this study. Therefore, the scholar employed all different types of strategies to protect the privacy of the site, the participants, and the related personnel. The signed and unsigned content forms and agreements, personal contacts, voice messages, written transcripts, and related materials were all locked in a password-protected cabinet. Only the scholar has the right(s) to read it. After the project is completed, the scholar deleted and destroyed the related materials 
immediately in order to protect the privacy of all the parties. The study was supported by Woosong University Academic Research Funding 2021/2022.

\section{FINDINGS}

Based on the shared materials and data, all participants answered the same interview protocol to enable the scholar to collect the opinions about the research question, based on the theoretical frameworks of Social Cognitive Career Theory and Social Cognitive Career and Motivation Theory (Dos Santos, 2018a, 2019b, 2020c, 2020d, 2021; Lent et al., 1994; Lent \& Brown, 1996).

This session summarised the voices of 12 participants. The following section explains how Social Cognitive Career Theory and Social Cognitive Career and Motivation Theory may connect to the motivations and reasons of these groups of parents (Dos Santos, 2018a, 2019b, 2020c, 2020d, 2021; Lent et al., 1994; Lent \& Brown, 1996). Please refer to Table 1 for the themes and subthemes.

Table 1

Themes and subthemes of the study

\begin{tabular}{l}
\hline Themes and Subthemes \\
\hline Academic Achievement \\
\hline Need to Take Additional Afterschool Programmes for Personal Development \\
\hline Develop Some Personal Goals and Achievements During the COVID-19 Pandemic \\
\hline Discipline \\
\hline Work Hard and Become Good Students and Children \\
Desires
\end{tabular}

\section{Academic Achievement}

\section{Need to Take Additional Afterschool Programmes for Personal Development}

First, all 12 participants indicated that, although public schools have no requirements for students to complete practice-based lessons from any online courses, parents argued that their students should continue some sports courses in order to gain expected outcomes from their further development and achieve better grades (for future exams). In line with the Social Cognitive Career Theory and Social Cognitive Career and Motivation Theory (Dos Santos, 2018a, 2019b, 2020c, 2020d, 2021; Lent et al., 1994; Lent \& Brown, 1996), parents positioned the academic achievement(s) of their students as very important. Therefore, the voices from parents reflected the elements of academic achievements and goals. The scholar learnt significant voices from the parents, as follows:

... my two children...should take sport courses...but, because of the government policy...no sports courses are available online in high school and middle school...I have to pay additional tuition fees to the afterschool programme...I want them to learn some good knowledge from teachers...regardless of the government policies (Participant \#1, Interview) 
...my kid needs to go to the afterschool programme...I believe it is essential for my kid to learn further skills beyond the high school curriculum...he can only study some traditional subjects online, such as biology and physics. What about sports... and some non-traditional subjects...therefore, I have to send him to the online afterschool programme...my son needs to have some achievements. (Participant \#4, Interview)

...my children and kids...received great education and certificates...from other types of channels...they must...be the best future leaders...in South Korea and Korean organisations...the afterschool programmes...for additional skills and knowledge...online will not influence our decision...all $I$ need is the learning...(Participant \#12, Focus Group Activities)

Based on the voices from the parents and the scholar's own reflections on Social Cognitive Career Theory and Social Cognitive Career and Motivation Theory (Dos Santos, 2018a, 2019b, 2020c, 2020d, 2021; Lent et al., 1994; Lent \& Brown, 1996), it is evident that the parents believed that sport and afterschool education could not be delivered due to government policy under the COVID-19 pandemic. In order to gain a source of sports skills, parents needed to send their students to an online afterschool programme to make up for the missing parts of the current school curriculum (due to the COVID-19 pandemic and online learning policy).

Need to Take Additional Afterschool Programmes to Meet Social Expectations

Second, some projects (Kim, 2009; Kwon et al., 2017) argued that the South Korean communities believed well-established backgrounds and academic results would offer them and their children better job opportunities and university decisions. University admissions teams like to recruit students with excellent grades, full extraordinary activities, and strong reference letters from teachers, counsellors, and NGO leaders. Because of the cultural expectations, parents decided to send their students to afterschool programmes, regardless of their delivery modes, in this case, online teaching. In line with Social Cognitive Career Theory and Social Cognitive Career and Motivation Theory (Dos Santos, 2018a, 2019b, 2020c, 2020d, 2021; Lent et al., 1994; Lent \& Brown, 1996), the following voices from four parents engaged to the element of academic achievements and goals:

If my kid does not go to the afterschool programme...can my kid apply to first-class universities? In our country [South Korea], universities and organisations assess people's academic results and the ranking of their educational institutions... if my kid won some of the Taekwondo competitions...my kid could join the first-ranked universities after secondary school...(Participant \#3, Interview)

... a lot of my children's classmates are currently enrolled in many programmes and courses from the afterschool programmes...such as music, mathematics, Chinese, and English to dancing...my children cannot miss these afterschool programmes...I asked my boys which courses they wanted to study...they told me Taekwondo. (Participant \#12, Interview) 
...school-aged students need to study hard and pay attention...these are the social and cultural expectations in South Korea...I used to live in this pressured society and community...even if I don't want to, the social pressure will ask my children to do so...the online course is not hard...but at least we need to do something...otherwise, my children will blame me in the future...(Participant \#2, Interview)

...Academic goals and achievements are some essential keys in South Korea...we have to provide training during their young age...children need to gain many certificates and some special skills...other than their peers and classmates...because we want them to understand this is the society...parents cannot just wait until...the graduated from high school...(Participant \#3, Focus Group Activity)

Based on the voices of parents, the scholar argued that social expectations and pressure from general public members play roles in parents' decisions and motivations (Amtu et al., 2020). Parents advocated that South Korean people and the communities compare people's backgrounds, academic achievements and overall performances because of the social pressure and competition. In line with social Cognitive Career Theory and Social Cognitive Career and Motivation Theory (Dos Santos, 2018a, 2019b, 2020c, 2020d, 2021; Lent et al., 1994; Lent \& Brown, 1996), the behaviours and decisions of these participants (i.e. parents) confirmed the element of academic achievements and goals (i.e., for both the desires of parents and social pressure).

Develop Some Personal Goals and Achievements During the COVID-19 Pandemic

Finally, all parents advocated that students do not need to go to school (physically) because of the social distancing recommendations. Thus, some additional times were available for further developments (i.e., in the area of hobbies and interests). Parents could spend extra financial resources (i.e. money) for afterschool programmes. In this case, with negotiation between their students, parents decided to send them to a martial arts afterschool programme for an online Taekwondo course. Kim (2009) argued that South Korean families generally save and spend a certain amount of their monthly budget for students' afterschool programmes and educational purposes. Two participants in this study confirmed this:

It is not a trend...I do not want them to become useless people in the community...but a requirement for Korean...people and students to attend afterschool programmes...after their traditional school period...my children don't need to go to school...because of the government policy...instead of playing computer games and watch TV at home... why don't they spend some time playing sports and learn some skills from the afterschool programmes...online is okay...(Participant \#9, Interview)

...it is useless to play games at home...I don't want my children to develop a meaningless hobby in computer games...It is not good at all...I asked them what afterschool programmes that they want to join...they don't like mathematics, and they don't like English. I asked them if they liked sports; they said yes. But our 
house cannot be a running field or basketball field, so let's try Taekwondo. (Participant \#10, Interview)

To sum up, the voices from the parents echoed Social Cognitive Career Theory and Social Cognitive Career and Motivation Theory (Dos Santos, 2018a, 2019b, 2020c, 2020d, 2021; Lent et al., 1994; Lent \& Brown, 1996), particularly the element of academic achievements and goals. Social expectations and pressure played important roles in parents' motivation and decisions. Although many agreed and argued that the online Taekwondo and related sport lessons might not be as good as in-person courses, they will spend financial resources on them. The academic achievements of their students are significant in motivating the afterschool programme selections and related decisions.

\section{Discipline of Study}

Besides the consideration of academic achievement, all 12 parents showed their understanding regarding discipline and discipline of study for traditional-age students. Due to traditional East Asian behaviours and the influences of/from Confucianism in South Korea, youths, particularly traditional-age students, are expected to earn perfect or near-perfect marks to show respect for their families.

\section{Work Hard and Become Good Students and Children}

The idea of filial piety (Hui et al., 2018) was repeated more than 80 times during the interview sessions and focus group activities. Like many East Asian groups and families, because of the expectations of/from Confucianism, South Korean people view filial piety as one of the most important behaviours and practices of their daily lives. All parents argued that their students should exercise their [parents'] plans to become good youths. Three participants, in particular, shared their ideas in this respect:

...why not follow the wise men...these are the rules in our Korean tradition. It is not something that I or we can break. I know it is very hard for my children. I want to play computer games too, but it is the responsibility of students to study... (Participant \#11, Interview)

...some rules and ideas are unclear in Korea...My kids are too young... to understand how society and company leaders... how bad those people and leaders are. I experienced that. I don't want them to fall into the same trap. They need to show people they are hard-working students and good students. Society will not let them go in such easy ways. (Participant \#8, Interview)

I know it is hard for all of us - parents, children, and even the teachers - but this is how it works in Korea...this is discipline... We have to follow the rules. (Participant \#7, Interview)

All parents advocated that the South Korean societies and the top managers expect exceptional backgrounds and excellent disciplines from the applicants and youths. In line with Social Cognitive Career Theory and Social Cognitive Career and Motivation Theory (Dos Santos, 2018a, 2019b, 2020c, 2020d, 2021; Lent et al., 1994; Lent \& 
Brown, 1996), excellent backgrounds and disciplines could lead to the element of academic achievements and goals. The expectation of good marks and well-established personalities established the motivations of the parents' decisions.

Children Should Take Afterschool Programmes and Courses Regardless of their Desires

The scholar further questioned the parents about what they may/might do if their students did not want to take any additional afterschool programmes - how would they react? Bousselaire (2017) has indicated that many South Korean students joined different types of afterschool programmes (i.e., based on personal desires or parental influence) (Choi \& Cho, 2016). In this case, the participants indicated that they let their students choose which afterschool programmes to join (i.e., subject matter). However, their students must take some afterschool programmes to meet their (parents') desires. Three significant comments are pertinent in this respect:

My children can select their own courses, but they have to take a course, an afterschool course at the academy. I have two boys and one girl. My girl is taking English and my second boy is taking mathematics. They can take whatever they want. It is free enough. (Participant \#5, Interview)

Afterschool programmes are important; they need to take them regardless of the subjects, from music to sport, but I need them to take it. (Participant \#6, Interview)

We have to send them to the afterschool programmes. This is not their own decision. They have to take the courses. Otherwise, how can they survive in our society. We need, and the employers need to see the certificate in the future. (Participant \#9, Focus Group Activity)

To sum up, this project confirmed that the motivations and reasons were influenced by Social Cognitive Career Theory and Social Cognitive Career and Motivation Theory (Dos Santos, 2018a, 2019b, 2020c, 2020d, 2021; Lent et al., 1994; Lent \& Brown, 1996), particularly the factor of academic achievements and goals. More importantly, the scholar found that parents decided to send their students to the afterschool programmes (in this case, the online martial arts course) mainly because of social and cultural expectations and pressures from the South Korean societies, peers, families, and communities. The South Korean communities expect positive and effective academic achievements and backgrounds from the next generations and young people. If their students do not meet these social and cultural expectations, the South Korean communities and leaders might neglect their existence. As a result, the parents decided to send their students to some afterschool programmes and courses, regardless of the teaching and learning modes and locations.

\section{Limitations and Future Developments}

Each study has its own limitation(s). The scholar indicated that there are two limitations in this study. First, the project investigated a single location (i.e. afterschool programme). However, parents from other backgrounds, expectations, financial 
backgrounds, and understanding of education may have different comments. Future projects may continue to discover voices from other schools and participants.

Second, the current project studied the course in sports and martial arts (i.e. Taekwondo). However, other practical-based and vocational-based courses and programmes may face a similar difficulty and problem. Therefore, future research projects may expand the directions and inquiries to other subject matters.

\section{Contribution to the Practice}

Three main contributions have been categorised. First, the results of this study serve as the blueprint for the government leaders, school leaders, policymakers, parents, students, and researchers to reform and polish their current policies and regulations about afterschool programmes and distance learning based programmes in the East Asian region, particularly the South Korean environment.

Second, school leaders and administrators may read this study and establish additional courses and programmes (i.e. both online and offline) in order to meet the expectations and needs of parents and students. Thus, although the COVID-19 pandemic will eliminate eventually, the demands of distance learning courses and programmes will become the trend in education.

Third, although learning is excellent for students' development, parents should listen to the expectations from their children. Children have the right(s) to select the courses and programmes for their interests. Therefore, the scholar hopes parents can release additional freedom for the students.

\section{CONCLUSION}

In conclusion, the COVID-19 pandemic, social distancing policies, and online learning development have re-directed the teaching and learning behaviours of many courses and programmes, including the practice-based and vocational-based subject matters. Based on the results of this study and the lens of the Social Cognitive Career Theory and Social Cognitive Career and Motivation Theory (Dos Santos, 2018a, 2019b, 2020c, 2020d, 2021; Lent et al., 1994; Lent \& Brown, 1996), South Korean parents might send their students to different online afterschool programmes and schools for academic enhancements. Although the online afterschool programmes might not have the same level of development as other in-person courses (benefit to their students), the social expectation and trend forced them to spend additional financial resources (i.e. money).

Second, although the practice-based and vocational-based programmes and courses (e.g. sport and martial arts courses) may not be beneficial if the teachers are delivered via online courses. Most participants (i.e. parents) continue to send their students to the online courses regardless of the outcomes and the results. The findings of this study confirmed the recommendations and guidelines of Social Cognitive Career Theory and Social Cognitive Career and Motivation Theory (Dos Santos, 2018a, 2019b, 2020c, 2020d, 2021; Lent et al., 1994; Lent \& Brown, 1996) about the element of academic achievements and goals. 


\section{ACKNOWLEDGEMENTS}

The research was supported by the Woosong University Academic Research Funding 2021.

This study was represented at the $13^{\text {th }}$ International Conference on Computer Supported Education in 2021.

\section{REFERENCES}

Amtu, O., Makulua, K., Matital, J., \& Pattiruhu, C. M. (2020). Improving student learning outcomes through school culture, work motivation and teacher performance. International Journal of Instruction, 13(4), 885-902. https://doi.org/10.29333/iji.2020.13454a

Bousselaire, S. (2017). Hagwon in South Korea. https://borgenproject.org/hagwonssouth-korea/

Brown, M., Hughes, H., Keppell, M., Hard, N., \& Smith, L. (2015). Stories from students in their first semester of distance learning. The International Review of Research in Open and Distributed Learning, 16(4). https://doi.org/10.19173/irrodl.v16i4.1647

Brown, S., \& Lent, R. (2019). Social cognitive career theory at 25: Progress in studying the domain satisfaction and career self-management models. Journal of Career Assessment, 27(4), 563-578. https://doi.org/10.1177/1069072719852736

Burdina, G. M., Krapotkina, I. E., \& Nasyrova, L. G. (2019). Distance learning in elementary school classrooms: An emerging framework for contemporary practice. International Journal of Instruction, 12(1), 1-16. https://doi.org/10.29333/iji.2019.1211a

Cavus, N. (2015). Distance learning and learning management systems. Procedia Social and Behavioral Sciences, 191, 872-877. https://doi.org/10.1016/j.sbspro.2015.04.611

Choi, J., \& Cho, R. (2016). Evaluating the effects of governmental regulations on South Korean private cram schools. Asia Pacific Journal of Education, 36(4), 599-621. https://doi.org/10.1080/02188791.2015.1064356

Dos Santos, L. M. (2018a). Career decision of recent first-generation postsecondary graduates at a metropolitan region in Canada: A social cognitive career theory approach. Alberta Journal of Educational Research, 64(2), 141-152.

Dos Santos, L. M. (2018b). Foreign language learning beyond English: The opportunities of One Belt, One Read (OBOR) Initiative. In N. Islam (Ed.), Silk Road to Belt Road (pp. 175-189). Springer.

Dos Santos, L. M. (2019a). Science lessons for non-science university undergraduate students: An application of visual-only video teaching strategy. Journal of Engineering and Applied Sciences, 14(1), 308-311. 
Dos Santos, L. M. (2019b). Recruitment and retention of international school teachers in remote archipelagic countries: The Fiji experience. Education Sciences, 9(2), 132. https://doi.org/10.3390/educsci9020132

Dos Santos, L. M. (2020a). Becoming a pre-school and elementary school educator: How do male teachers describe their career decision and career development from the perspective of the social cognitive career approach and human resource management. Journal of Education and E-Learning Research, 7(2), 159-166. https://doi.org/10.20448/journal.509.2020.72.159.166

Dos Santos, L. M. (2020b). The motivation and experience of distance learning engineering programmes students: A study of non-traditional, returning, evening, and adult students. International Journal of Education and Practice, 8(1), 134-148. https://doi.org/10.18488/journal.61.2020.81.134.148

Dos Santos, L. M. (2020c). How does COVID-19 pandemic influence the sense of belonging and decision-making process of nursing students: The study of nursing students' experiences. International Journal of Environmental Research and Public Health, 17(15), 5603. https://doi.org/10.3390/ijerph17155603

Dos Santos, L. M. (2020d). I want to become a registered nurse as a non-traditional, returning, evening, and adult student in a community college: A study of careerchanging nursing students. International Journal of Environmental Research and Public Health, 17(16), 5652. https://doi.org/10.3390/ijerph17165652

Dos Santos, L. M. (2021). Developing bilingualism in nursing students: Learning foreign languages beyond the nursing curriculum. Healthcare, 9(3), 326. https://doi.org/10.3390/healthcare9030326

Dos Santos, L. M. (2020e). Employing a technologically-assisted teaching and learning strategy in the English as a foreign language classroom: The application of the visualonly video teaching strategy. International Conference on Open and Innovative Education, 143-156.

Elyakim, N., Reychav, I., Offir, B., \& McHaney, R. (2019). Perceptions of transactional distance in blended learning using location-based mobile devices. Journal of Educational Computing Research, 57(1), 131-169. https://doi.org/10.1177/0735633117746169

Espino, J., Suárez, M., \& González-Henríquez, J. (2020). Video for teaching: Classroom use, instructor self-production and teachers' preferences in presentation format. Technology, Pedagogy and Education, 29(2), 147-162. https://doi.org/10.1080/1475939X.2020.1726805

Flores, L. Y., \& O’Brien, K. M. (2002). The career development of Mexican American adolescent women: A test of social cognitive career theory. Journal of Counseling Psychology, 49(1), 14-27. https://doi.org/10.1037/0022-0167.49.1.14

Freer, E., \& Evans, P. (2019). Choosing to study music in high school: Teacher support, 
psychological needs satisfaction, and elective music intentions. Psychology of Music, 47(6), 781-799. https://doi.org/10.1177/0305735619864634

Gibbons, M. M., \& Shoffner, M. F. (2004). Perspective First-Generation College Students: Meeting Their Needs Through Social Cognitive Career Theory. Professional School Counseling, 8(1), 91-97.

Hui, T., Yuen, M., \& Chen, G. (2018). Career-Related Filial Piety and Career Adaptability in Hong Kong University Students. The Career Development Quarterly, 66(4), 358-370. https://doi.org/10.1002/cdq.12156

Kim, I. (2009). The Role of Self-Efficacy and Social Support in the Relationship between Emotional Labor and Burn out, Turn over Intention among Hospital Nurses. Journal of Korean Academy of Nursing Administration, 15(4), 515-526.

Kwee, C. (2020). The application of career theories in teachers' professional development and career decision: A literature review. Universal Journal of Educational Research, 8(9), 3997-4008. https://doi.org/10.13189/ujer.2020.080925

Kwon, S., Lee, M., \& Shin, D. (2017). Educational assessment in the Republic of Korea: lights and shadows of high-stake exam-based education system. Assessment in Education: Principles, Policy \& Practice, 24(1), 60-77. https://doi.org/10.1080/0969594X.2015.1074540

Lantz, J. (2002). Family development and the martial arts: A phenomenological study. Contemporary Family Therapy, 24(2), 565-580.

Lassoued, Z., Alhendawi, M., \& Bashitialshaaer, R. (2020). An exploratory study of the obstacles for achieving quality in distance learning during the COVID-19 pandemic. Education Sciences, 10(9), 232. https://doi.org/10.3390/educsci10090232

Lent, R. W., \& Brown, S. D. (1996). Social cognitive approach to career development: An overview. The Career Development Quarterly, 44(4), 310-321. https://doi.org/10.1002/j.2161-0045.1996.tb00448.x

Lent, R. W., Brown, S. D., \& Hackett, G. (1994). Toward a unifying social cognitive theory of career and academic interest, choice, and performance. Journal of Vocational Behavior, 45(1), 79-122. https://doi.org/10.1006/jvbe.1994.1027

Merriam, S. B. (2009). Qualitative research: A guide to design and implementation. Jossey Bass.

Nosanchuk, T. (1981). The way of the warrior: The effects of traditional martial arts training on aggressiveness. Human Relations, 34(6), 435-444.

Petrenko, L., Kravets, S., Bazeliuk, O., Maiboroda, L., \& Muzyka, I. (2020). Analysis of the current state of distance learning in the vocational education and training $\begin{array}{lllll}\text { institutions. } & E 3 S & W & \end{array}$ https://doi.org/10.1051/e3sconf/202016610010

Santagata, R., \& Guarino, J. (2011). Using video to teach future teachers to learn from 
teaching. $\quad Z D M \quad$ Mathematics Education, 43(1), 133-145. https://doi.org/10.1007/s11858-010-0292-3

Simpson, O. (2018). Supporting students in online, open and distance learning. Routledge. https://doi.org/10.4324/9780203417003

Tang, K. H., \& Dos Santos, L. M. (2017). A brief discussion and application of interpretative phenomenological analysis in the field of health science and public health. International Journal of Learning and Development, 7(3), 123-132. https://doi.org/10.5296/ijld.v7i3.11494

Thomas, D. R. (2006). A general inductive approach for analysing qualitative evaluation data. American Journal of Evaluation, 27(2), 237-246. https://doi.org/10.1177/1098214005283748

Thompson, M. N., Dahling, J. J., Chin, M. Y., \& Melloy, R. C. (2017). Integrating Job Loss, Unemployment, and Reemployment With Social Cognitive Career Theory. Journal of Career Assessment, 25(1), 40-57. https://doi.org/10.1177/1069072716657534

Weiner, L. (2012). The future of our schools: teachers unions and social justice. Haymarket Books.

Weiner, L., \& Jerome, D. (2016). Urban teaching: The essentials (3rd ed.). Teachers College Press.

Yamagata-Lynch, L. C., Do, J., Skutnik, A. L., Thompson, D. J., Stephens, A. F., \& Tays, C. A. (2015). Design lessons about participatory self-directed online learning in a graduate-level instructional technology course. Open Learning: The Journal of Open, $\begin{array}{llll}\text { Distance } & \text { and } & \text {-Learning, } & \text { 178-189. }\end{array}$ https://doi.org/10.1080/02680513.2015.1071244

Yin, R. K. (2012). Applications of case study research (3rd ed.). SAGE Publications. 